\title{
SDWAN (Software Defined-WAN) Technology Evaluation and Implementation
}

By Anshuman Awasthi

Abstract- Many organizations are struggling to provide high bandwidth and reliable internet connectivity at their branch offices and business locations and getting the most out of their operational expense. The need for internet connectivity at any branch offices and business locations is no longer a luxury but is a necessity. Let us try to understand how to replace the traditional MPLS network with the new SDWAN (Software - Defined- Wide Area Network) technology. We will try to understand why it is essential to implement the latest technology instead of investing in the existing MPLS (Multi- Protocol label switching) by taking an example of a retail organization. We also have a look at how to evaluate the product by using some metrics and how different teams are involved during different phases of the project.

Keywords: network engineering, SDWAN implementation, $R O I$ analysis, technical project management, MPLS replacement.

GJCST-C Classification: C.2.m

Strictly as per the compliance and regulations of:

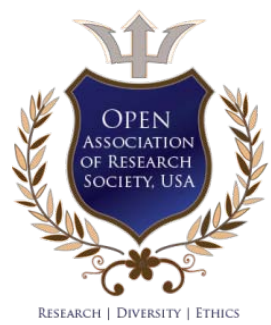

(C) 2020. Anshuman Awasthi. This is a research/review paper, distributed under the terms of the Creative Commons AttributionNoncommercial 3.0 Unported License http://creativecommons.org/licenses/by-nc/3.0/), permitting all non commercial use, distribution, and reproduction in any medium, provided the original work is properly cited. 


\title{
SDWAN (Software Defined-WAN) Technology Evaluation and Implementation
}

\author{
Anshuman Awasthi
}

\begin{abstract}
Many organizations are struggling to provide high bandwidth and reliable internet connectivity at their branch offices and business locations and getting the most out of their operational expense. The need for internet connectivity at any branch offices and business locations is no longer a luxury but is a necessity. Let us try to understand how to replace the traditional MPLS network with the new SDWAN (Software Defined- Wide Area Network) technology. We will try to understand why it is essential to implement the latest technology instead of investing in the existing MPLS (MultiProtocol label switching) by taking an example of a retail organization. We also have a look at how to evaluate the product by using some metrics and how different teams are involved during different phases of the project.
\end{abstract}

Keywords: network engineering, SDWAN implementation, $\mathrm{ROI}$ analysis, technical project management, MPLS replacement.

Methods: This project/research was performed using the abilities of Software Defined Network Technology and options available in MPLS (Multi-Protocol Label Switching). The Technical Project management principles were adopted as per PMI (Project Management Institute) waterfall methodology.

Results/Conclusion: SDWAN technology provides an adequate replacement of the MPLS network connection for providing WAN connectivity for our office locations. It is essential to follow a documented process for appropriate vendor selection based on the available features and other listed attributes in the article. To increase the chances of the success in the implementation, it is essential to perform a POC (Proof of Concept) in a controlled environment and validate results. SDWAN provides better network performance and improves reliability as the links operate in activeactive function.

\section{InTRODUCTION}

$\Lambda$ retailer has to perform several transactions in a business location, and there is a need for a reliable high-bandwidth internet circuit. In the absence of a high-speed internet connection, many sites may report slow internet performance as they may be running on a single high-cost low-bandwidth internet connection. This initiative targets to deploy SDWAN technology at all the business locations. The IT Network Engineering team of an organization can lead this

\footnotetext{
Author: Director - Engineering, Restoration Hardware.
} e-mail: anshumanawasthi@yahoo.com initiative, but as this is a cross-functional project. It will need help from different groups like IT Operations for Server and Storage requirements, Business Support for coordination with Business Associates, Network Administrator, and Onsite Tech support team. They will be responsible for device installation at all galleries. In addition to these stakeholders, we need to have a dedicated Project Manager (PM) to monitor the project's overall progress, who will coordinate with $\mathrm{COO}$ for any budgetary issues and with VP -Infrastructure to allocate necessary organizational resources. The designated PM will work closely with Director Project Management Office to ensure the scheduled tasks for this project do not interfere with the plans in other areas of the business as the company has multiple projects in progress at the same time. This Project has four phases Design, Initial Implementation, Rollout, and Project Closure. We will estimate the average internet bandwidth upgrade and percentage increase in network and hardware reliability by reviewing the incident data post-upgrade to calculate the overall success of the project.

a) Cause

Below factors are contributing to the poor network performance and causing unreliable network connection at several business locations.

- Most of the business locations have a high-cost low-bandwidth Private WAN (Wide Area Network) circuit. This circuit is very reliable but does not solve the increasing demand for high-bandwidth.

- Many locations are just operating on a single Private WAN circuit. Very few locations have a reliable secondary network connection.

- The business locations with dual circuits cannot utilize bandwidths effectively, as due to technical limitations, they are operating on Active/Passive mode. (Only one connection can be operational at one time).

\section{b) Proposed Solution}

The existing technology using traditional network architecture is undoubtedly unable to provide a solution that can solve our needs and still be affordable. The time has come to explore the capabilities of the SDWAN (Software - Defined Wide Area Network) solution. According to Wikipedia (n.d.), an SD-WAN simplifies the management and operation of a WAN by decoupling (separating) the networking hardware from its control mechanism. This concept is similar to how 
software-defined networking implements virtualization technology to improve data center management and operation.

An essential application of SD-WAN is to allow companies to build higher-performance WANs using lower-cost and commercially available Internet access, enabling businesses to partially or entirely replace more expensive private WAN connection technologies such as MPLS.

\section{Evaluation}

\section{a) Evaluation Approach}

If the organization decides to implement SDWAN technology at all the business locations to improve the network performance and reliability, the IT Network Team can estimate the new bandwidth requirement using Solarwinds NPM (Network Performance Monitor) tool. The team should monitorall the interfaces of network devices at business locations and gather data about current usage; we can make use of this to estimate the required bandwidth of new circuits at each location.

The needs, as mentioned earlier from the new technology, will help to decide on the metrics to evaluate the project's success. In addition to the network performance parameters, we can also add some service and operational improvement data points to improve the overall experience of the employees concerning this project. The inclusion of service improvement metrics in the project's success will also ensure the vendors involved in the project to provide quality service since we will evaluate their performance as a part of the project's success.

\section{b) Quality Assurance Criteria (Metrics)}

We can use below Metrics as a reference to measure the proposed and actual outcomes of the project.

\begin{tabular}{|c|l|l|l|}
\hline Evaluations Area & Proposed \% & Actual \% & $\begin{array}{c}\text { Business } \\
\text { Feedback }\end{array}$ \\
\hline Internet Bandwidth Upgrade & & & \\
\hline Network Reliability & & & \\
\hline Hardware Reliability & & & \\
\hline Ease of Installation & & & \\
\hline Ease of Access & & & \\
\hline Network Management & & & \\
\hline Security Policies Management & & & \\
\hline Vendor Support & & & \\
\hline
\end{tabular}

We can evaluate the network performance using a tool that is an industry leader in performing a speed test called OOKLA. To measure the overall network performance and compare the pre and postinstallation results, we can use Solarwinds NPM (Network Performance Monitor). To measure incident ticket count and ease of administration using the incident resolution time matrix, we can use any ticketing tool like Service Now, one of the most popular Cloudbased ticketing systems in the industry today. We should only select an SDWAN partner once theyprovide supporting documentation that their product has passed the necessary security and health safety tests. The organization can also perform a vulnerability test once the product is installedat its first location to ensure there are no new vulnerabilities discovered in the network.

\section{c) Solution Testing}

To perform extensive testing with the new SDWAN solution provided by the vendor, the project team needs to work on a test location where they can replace the old router with the latest hardware and perform connectivity tests. The SDWAN technology partner can providean appliance for the testing purpose; the organizationIT team can use the new hardware with the old network switch if the experts from theSDWAN team confirms that there will be no compatibility issues.

Please refer below the list of activities and observations as a reference that we need to execute every day to test the SDWAN hardware and software. The list of activities and the number of days required for testing are as per the use case.

\begin{tabular}{|c|}
\hline Location to be tested: Pleasanton (PL),CA \\
\hline Person in-charge for testing:Name1,Name2 \\
\hline \\
\hline Thursday 1st Oct Activity \\
\hline Day1 -Activity \\
\hline $\begin{array}{c}\text { Created new Policy with Standard format and added ABC.com, Google, Yahoo,Linked In to choose all Network } \\
\text { Paths }\end{array}$ \\
\hline Switched On SDWAN-Observed 8 Ping Loss \\
\hline
\end{tabular}


From Pleasanton to Data Center average response time is $7 \mathrm{~ms}$

Turned on SDWAN at PL-Took around 2mins for steady response

Disconnected MPLS from providers end

\section{Day1 -Observations}

First -Internet and Datacenter Sites were reachable. MPLS sites were not reachable.

Second-Internet went down. Data Center sites were reachable

Internet went down and didn't come up

All sites went down

Connected MPLS Router back-connectivity is restored

Disconnected MPLS from WAN port for SDWAN

First, only connectivity to Datacenter was up

Then connectivity to all sites went down

Connected MPLS back to original state-all sites were online

\section{Observation-Traffic is going to a blackhole- Needs investigation}

\begin{tabular}{|c|}
\hline Day 2 -Activity \\
\hline The modified Linkedln policy only to use MPLS and Internet( No Internet VPN) \\
\hline Added 8.8.8.8 as DNS in SDWAN in PL as DNS along with Infoblox as the third option \\
\hline Disconnect Router WAN connection \\
Day 2 -Observations \\
\hline Linked was working but Yahoo and YouTube didn't work-Cannot ping to any internet sites \\
\hline YouTube and Gmail was added to use the Direct Internet path and not to use Internet VPN \\
\hline YouTube is working very slow \\
\hline Direct Internet websites response is very slow and not reliable \\
\hline Observation- Needs more investigation on high latency in direct internet response \\
\hline Connected SDWAN appliance back \\
\hline We switched back to original policies where we started \\
\hline
\end{tabular}

\section{Day 3 -Activity}

Validate All policies in Pleasanton

Add floating static Routes in on Rack 7 and Rack 6 Edge switches at Data Center for Pleasanton office

Change all applications listed in SDWAN policies to use a dual path

1. Organization Websites- All Routes

2. Symantec- Internet VPN +MPLS

3. Google- All Routes

4. YouTube- All Routes

5. Linkedln- All Routes

6. Casper ( Software management on MACs)- Internet VPN + MPLS

7. Yahoo Mail- All Routes

8. Google Hangout- All Routes

Start continuous ping to few websites

Disconnect Internet Circuit from SDWAN (Observe for any blips) 


\begin{tabular}{|c|}
\hline Connect Internet Circuit \\
\hline Start Continues ping to few websites \\
\hline Disconnect MPLS Circuit from SDWAN (Observe for any blips) \\
\hline Connect MPLS circuit to SDWAN (bypass Cisco Router) \\
\hline Perform Trace route to Data Center, Internet Sites,P2P(Point to Point), and MPLS sites \\
\hline Day 3 -Observations \\
\hline Check Core Switch in Data Center for new routes \\
\hline Check MPLS Router in Data Center for new routes \\
\hline Is MPLS working in Pleasanton -Yes \\
\hline
\end{tabular}

\begin{tabular}{|c|}
\hline Day 4 - Activity \\
\hline Connect MPLS back to Verizon Box \\
\hline We had intermittent connectivity to complete connectivity loss \\
\hline Tried rebooting the Verizon device \\
\hline Tried rebooting MPLS router \\
\hline Disconnect internet circuit from SDWAN \\
\hline Day 4 -Observations \\
\hline Stable connection \\
\hline Able to browse to yahoo, google \\
\hline
\end{tabular}

Test Cases

\begin{tabular}{|c|}
\hline Day 5-Activity \\
\hline Upgrade Image on PleasantonSDWAN to 0.16.4 \\
\hline Internet +MPLS (MPLS is already connected just connect Internet) \\
\hline Day 5 -Observations \\
\hline We had intermittent connectivity to complete connectivity loss to internet websites \\
\hline
\end{tabular}

\begin{tabular}{|c|}
\hline Day 6-Activity \\
\hline Upgraded to version 0.185 on Hub and SDWAN \\
\hline Connected Internet Circuit \\
\hline Day 6 -Observations \\
\hline Stable connection \\
\hline Able to browse to yahoo, google \\
\hline
\end{tabular}

After multiple days of testing and running measure performance attributes and operational different scenarios, we can reach a stable image and improvements. network architecture.

\section{d) Acceptance Criteria and Evaluation Framework}

The Project Teamcan make a list of the abilities

for the product acceptance criteria. It will also help to

\begin{tabular}{|c|}
\hline Evaluations Area \\
\hline Internet Bandwidth Upgrade \\
\hline Network Reliability \\
\hline Hardware Reliability \\
\hline Ease of Installation \\
\hline Ease of Access \\
\hline Network Management \\
\hline Security Policies Management \\
\hline Vendor Support \\
\hline
\end{tabular}


The Project Manager, along with the help of Leadership and other teams, can perform the CostBenefit Analysis. Please refer below Cost Analysis for developing, installing, and supporting an SDWAN appliance at a business location. To justify the investment (project cost), we have also put together some data on how much time we are spending on the support of maintenance of existing network infrastructure and incidents that are occurring due to the bandwidth and technology limitations. It is essential to make a note of the financial loss we have to suffer in case of an internet outage at a business location.

Please refer below Cost Analysis table as a reference.

\begin{tabular}{|c|c|}
\hline \multicolumn{2}{|l|}{ Cost -Benefit Analysis of using SDWAN as Internet Appliance at Locations } \\
\hline Projects Costs per Location & Amount \\
\hline \multicolumn{2}{|l|}{ Datacenter Hardware } \\
\hline Datacenter Hub -Product Design and Development & -- \\
\hline Site Hardware & -- \\
\hline Software \& Licenses & -- \\
\hline Support ( Included in License) & -- \\
\hline Internal - Labor ( $\$ 75 /$ hour) -Installation 2 hour per location & -- \\
\hline External -Labor (\$125/ hour)-Installation 4 hour per location & -- \\
\hline Internet Connection 1 -Monthly Recurring Charge per location & -- \\
\hline Internet Connection 2--Monthly Recurring Charge per location & -- \\
\hline Total Capital Expense for each Location ( Only First Year) & -- \\
\hline Total Operational Expense for each Location & -- \\
\hline \multicolumn{2}{|l|}{ Current Costs ( Project Cost Justification) } \\
\hline Current Site Hardware Support & -- \\
\hline Current Datacenter Hardware Support \& Maintenance & -- \\
\hline Internal - Labor ( $\$ 75 / \mathrm{hr}$ ) - To solve Incidents & -- \\
\hline External -Labor (\$125/ hr) - For Technician & -- \\
\hline Internet Connection 1 & -- \\
\hline \multicolumn{2}{|l|}{ Loss in revenue due to internet outage (per hour) } \\
\hline Large locations & -- \\
\hline Small Locations & -- \\
\hline Total Operational Expense & -- \\
\hline Revenue Loss per hour for each location ( Outages-Due to old Technology/Hardware) & -- \\
\hline
\end{tabular}

It can become very clear from the above CostBenefit Analysis that the organizations are spending considerable amounts in supporting the existing technology and not getting any benefits in return. It is advisable to invest in the new technology and avoid these outages so that we can run our business smoothly. The modern technology architecture is centrally managed through a cloud-based controller and needs minimum operational expenditure post implementation.

In addition to the above-mentioned acceptance criteria, which includes Cost-Benefit analysis, hardware/ technology performance the project team should involve the legal team to create an MSA (Master Service Agreement) which includes some pre-checks to ensure the vendor is following all the environmental and legal obligations like the validation of their W9 form, tax returns. Once we got a go-ahead from all the different teams, the project team collectivity decided a partner to work.

\section{ili. Project Review}

\section{a) Phases \& Milestones}

The SDWAN implementation project has four phases, with below listed main milestones in each group.

First Phase: SDWAN Design

- Identify what SDWAN has to offer

- Research available SDWAN vendors

- Finalize an SDWAN Vendor

- Shortlist a vendor and perform a POC

This phase will lay the foundation stone for the project; the project team needs to be aware of the fact 
that if they make a wrong decision at this stage or they miss on a critical test scenario to evaluate the product, it can take the whole project to the failure. The Project Manager needs to spend a lot of time with the technical Teams to document all the evaluation parameters to ensure we select the appropriate SDWAN technology partner. It is essential to make all the configuration changes in the test environment before we say that the technology is ready to be implemented in production. At the end of this,the team can select an SDWAN partner that provides relevant documentation to integrate the new technology into the existing enterprise network. The team should also evaluate their assumptions and carefully recorded various network performance parameters.

\section{Second Phase: Initial Implementation}

- Implement a solution in the first location and evaluate results

- Implement the solution in five more locations

The activities in this phase are essential before the team goes into the full rolloutphase, as it ishelpful to implement the solution on a smaller scale, collect feedback, and make final configuration changes. This phase will help the team to fine-tune their skills required in the rollout phase to implement the solution in multiple locations. The Network team should work with the onsite operations to install the SDWAN hardware in the first

- $\quad$ Existing Setup location. If the new technology andequipment's verification in the previous phase,there should be no big surprises. Still, there can bemany learnings that can help the team to prepare a precise playbook that should be followed by the technicians for the installation of the hardware in the other locations.

\section{Third Phase: Rollout}

- Implement the final solution in the remaining Business and Office locations

- Review results with the Operations team and Management

- Prepare Training and Documentation

In thisstage, all hands on deck are required. The team should feel confident about the solution, as we have done enough testing during the earliertwo stages. The PM helped to coordinate all the scheduled tasks and allocate resources as per the plan. The Support Team should work with the Network Administrators and Onsite Tech for the installation and configuration of the SDWAN hardware. The project team can prepare a detailed playbook on what steps to follow along with the diagrams for the device installation and perform application testing.

Please refer below diagram for reference, showing steps for connecting SDWAN devices in a location. 


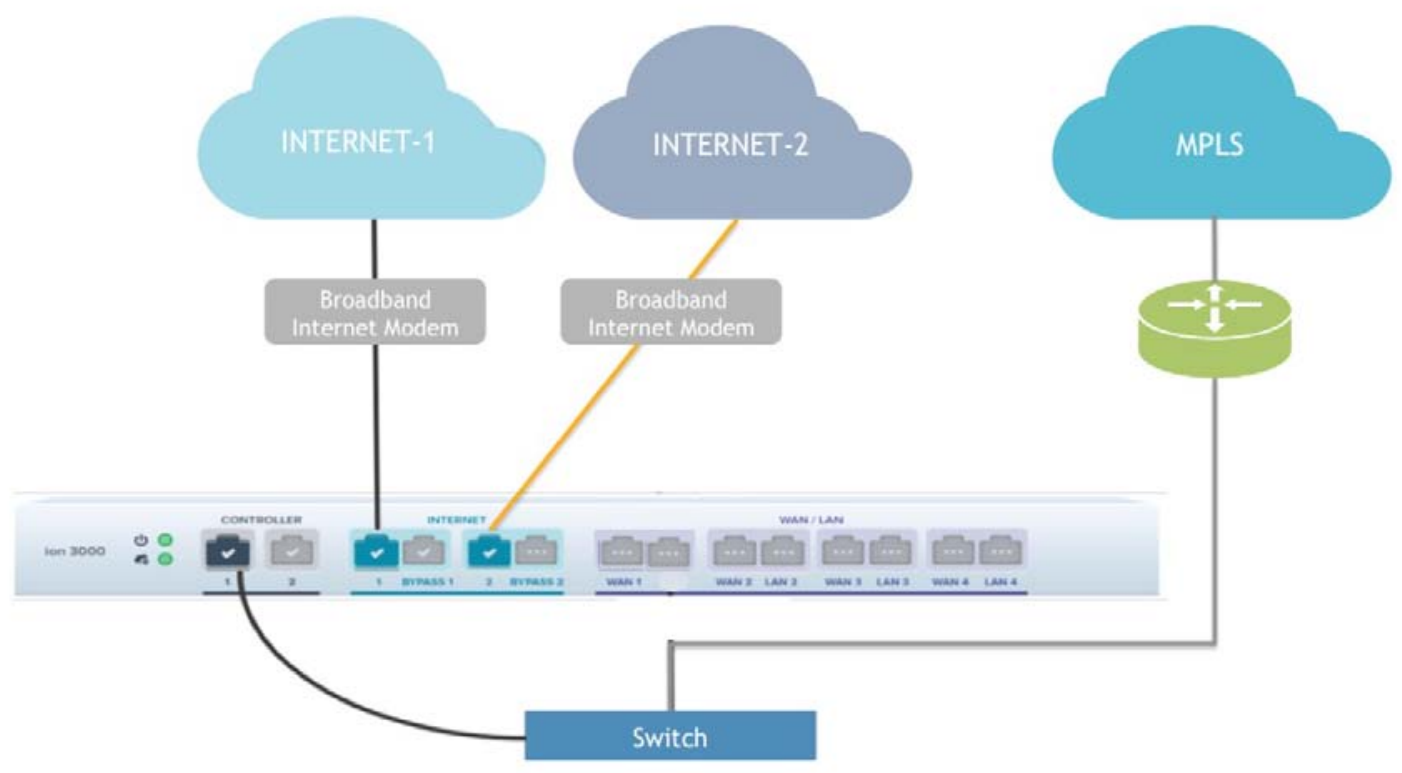

- Step 2- Move Router link to SDWAN appliance

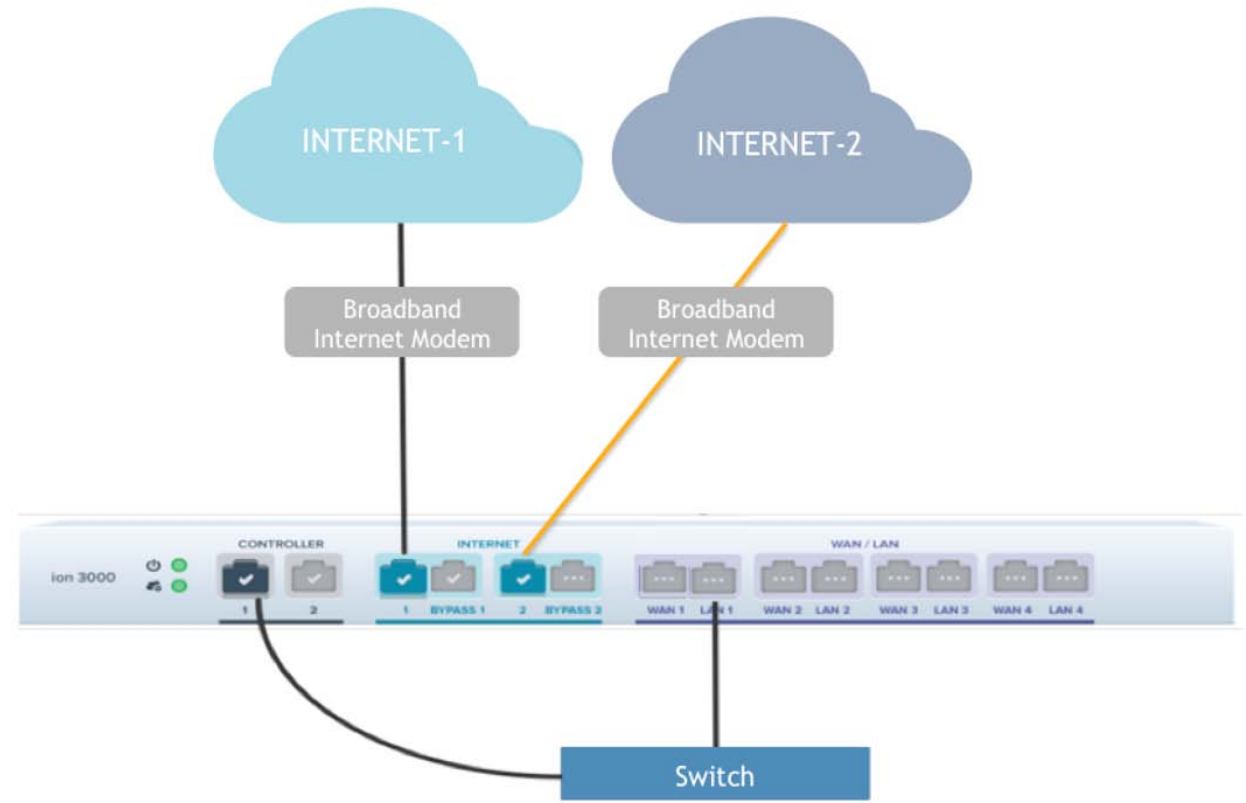

The Project Team can prepare a detailed set of instructions for technicians on what equipment's/tools are required to perform the installation. Please refer toa sample of instructions.

The objective of this visit is to visit the business location and complete the Network Conversion to make Primary and MPLS Router/Failover on the new SDWAN device using the equipment on Day 1. You will work with the Network Team before making any cable move.

b) Equipment Needed by Tech

- Working computer with working NIC

- Cat5 Ethernet Cable

- Null Modem Cable (Console cable)

- Punch down tool

- Label Maker c) Hardware to be Found Onsite

- Broadband Wireline Modem

- SDWAN Device

- $\quad$ Red, White, and Green patch cables

The Project team can create a list of tests to perform application testing post-installation. A sample of test instructions is mentioned below:

Once you have made the connection updates and the Network contact has confirmed the network is up, request the location Leader to follow below test plan:

- Test iPad to connect to Organization's Intranet website

- Test iPad to Gmail

- Test iPad to CNN.COM

- Test iPad for printing 
- Test POS (Point of Sale) for printing

- Test POS for $\$$ transactions-look for an item

- Test PC for Internet

- Test PC for printing

- Test wireless phone for an incoming and outgoing call

With the help of these installation details, along with the helpful diagrams and test instructions, the installation crew can perform installations successfully. The PM needs to schedule conference calls to review past installations so that we can learn from the mistakes and make necessary changes for future installs.

\section{Fourth Phase: Project Closure}

- Conduct Training for Operations and Support Team

- Handover to Operations

- Update Integrations with Incident Management Tool

- Prepare Project Closure Documentation

According to MOP (n.d.) Project closure activities ensure the recording project documents, archiving in organizational process assets, making final payments, releasing resources, and completing the project. Every project teaches lessons to the organization, whether it is a success, or it is a failure. So even after a project finishes, the documentation of this project will be helpful for completing the future projects successfully.

During this phase, the PM worked with the Project Technical team like Network and SDWAN partner to create documentation that includes the below details.

- How to support the new SDWAN technology

- How to perform daily administrative tasks

- How to troubleshoot any wireless network issues with SDWAN device.

Please refer sample of instructions as a reference that can be created by the project team to handover to operations.

- $\quad$ Path Selection process

Edit "CNN-Policy"

Select Paths

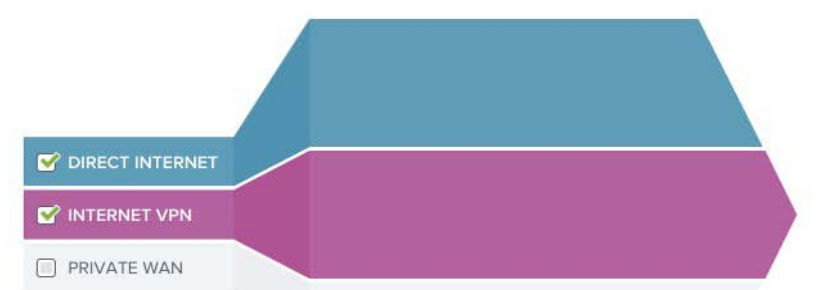

Cancel

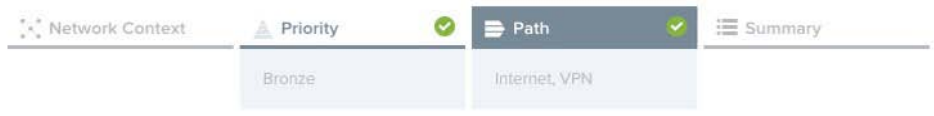

- How to check Device Status

Red indicates the device has no power:

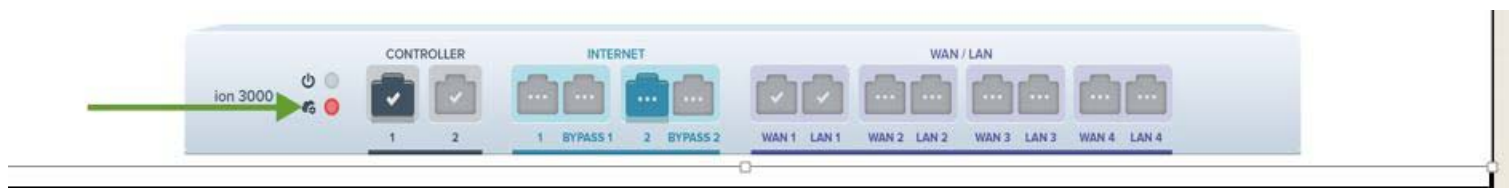

Green indicates the device has power:

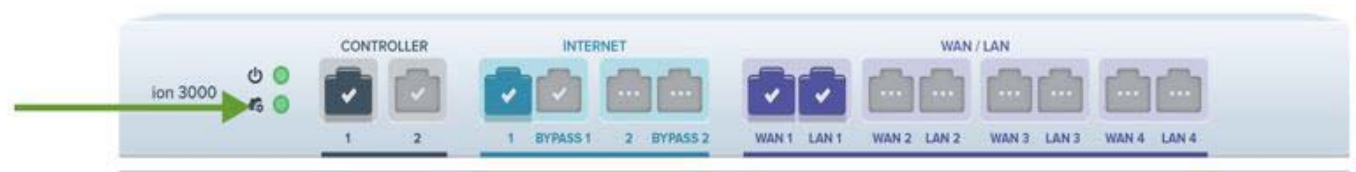

Solid color means configured and connected: 


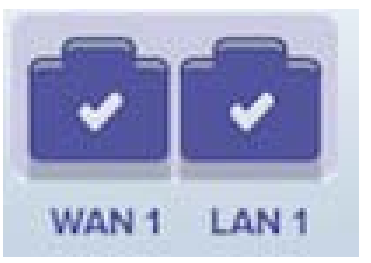

Not configured and No connection:

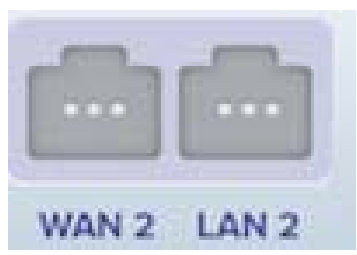

Ports configured but not connected:

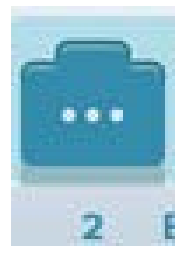

The PM should schedule few trainings for the support team members. The technical team members who performed the actual implementation should lead the training sessions. It is due to the detailed support documents and the training workshop; the support team can gain the confidence to work on the new technology.

The PM needs to work with the IT Operations team to integrate the new technology with the existing enterprise applications. Once we have completed all the necessary administrative tasks, including paying the due invoices and reviewing actual time spent vs. time allocated, the PM should send a project closure report to the management and all the stakeholders involved.
Timeframe:

Please refer below chart to compare the planned vs. actual period as a reference. The team may encounter some initial challenges during the testing phase due to which they may have to extend the SDWAN design phase by sometime. As mentioned in the previous section, the team prepared very detailed installation instructions to expedite the installations. We have highlighted the estimated timeline in grey, and the actual time it took is done in red.

\begin{tabular}{|c|l|l|l|l|l|l|l|}
\hline Duration & Week1 & Week2 & Week3 & Week4 & Week5 & Week6 & Week7 \\
\hline Phases & & & & & & & \\
\hline SDWAN Design-Planned & & & & & & & \\
\hline SDWAN Design-Actual & & & & & & & \\
\hline Identify what SDWAN has to offer & & & & & & & \\
\hline Research available SDWAN vendors & & & & & & & \\
\hline Finalize a SDWAN Vendor & & & & & & & \\
\hline Shortlist a vendor and perform a POC & & & & & & & \\
\hline Initial Implementation-Planned & & & & & & & \\
\hline Initial Implementation-Actual & & & & & & & \\
\hline $\begin{array}{c}\text { Implement solution in first location and } \\
\text { evaluate results }\end{array}$ & & & & & & & \\
\hline Implement solution in five more locations & & & & & & & \\
\hline Roll out -Planned & & & & & & \\
\hline Roll out -Actual & & & & & & \\
\hline $\begin{array}{c}\text { Implement final solution in remaining } \\
\text { locations and outlet locations }\end{array}$ & & & & & & & \\
\hline $\begin{array}{c}\text { Review results with the Onsite operations } \\
\text { team and Management }\end{array}$ & & & & & & & \\
\hline Prepare Training and Documentation & & & & & & & \\
\hline
\end{tabular}




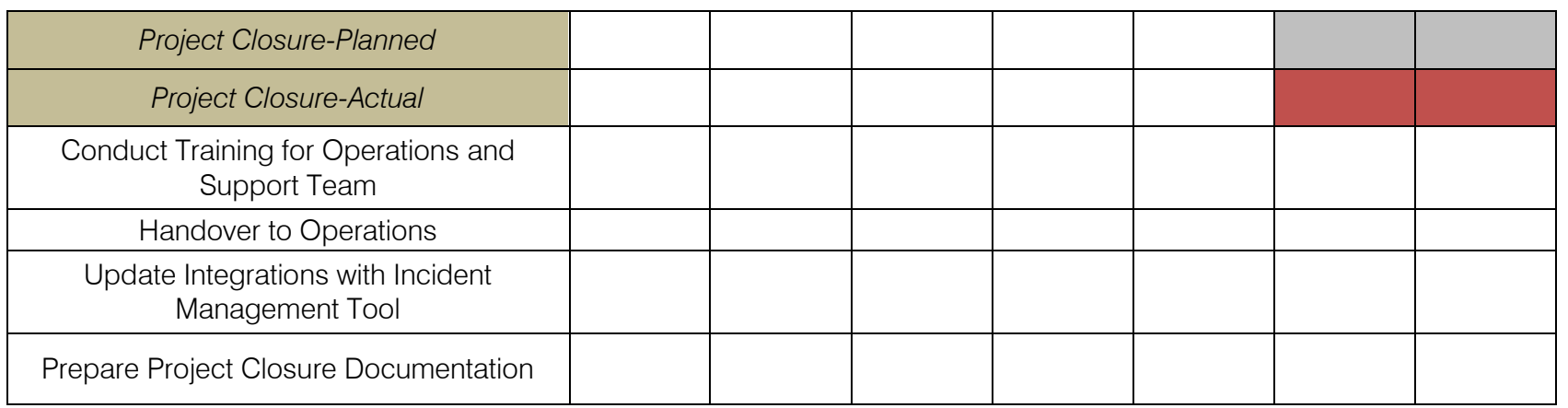

\section{d) Dependencies}

In this project, each phase can relate to other phases in sequence. Hence, the tasks associated with each phase also had a sequential relationship with each other (Dependent Tasks are highlighted in each phase in the timelines section). However, action items in the project closure phase were supposed to be carried out concurrently (Tasks in the project closure phase are not highlighted). The project team members should perform the tasks as per the plan.

e) Resources

\begin{tabular}{|c|c|c|c|c|}
\hline \multirow{2}{*}{ Skills } & \multicolumn{3}{|c|}{ Project Phases (Estimated hours)- Only for Reference } \\
\hline & Project Initiation & $\begin{array}{c}\text { Initial } \\
\text { Implementation }\end{array}$ & Roll Out & Project Closure \\
\hline Phase Duration & 2 weeks & 1 week & $2-3$ weeks & $1-2$ weeks \\
\hline Project Manager & 40 & 30 & 30 & 70 \\
\hline Network Architect & 60 & 30 & 10 & 40 \\
\hline $\begin{array}{c}\text { Network } \\
\text { Administrator }\end{array}$ & 20 & 50 & 200 & 50 \\
\hline Onsite Support & 10 & 20 & 100 & 60 \\
\hline IT Operations & 10 & 20 & 70 & 20 \\
\hline SDWAN Partner & 30 & 20 & 100 & 50 \\
\hline
\end{tabular}

\section{f) Milestones}

The project team can plan for below milestones based on the implementation strategy.

- Finalizing an SD-WAN vendor

- Finalizing the network design with the SD-WAN vendor

- Implementing SD-WAN technology in the initial pilot location

- Reviewing performance results with the project team and management

- Obtaining approval to proceed with the rollout

- Implementing SD-WAN technology in all the locations

- Handing over to operations

g) Deliverables (Hardware and Software)

- SD-WAN hardware installation in all office locations

- Dual direct internet access circuit installation at all locations

- Network policy configuration for SD-WAN software

- Security policy configuration for SD-WAN software

h) Implementation Plan for Documenting Deliverables

The project team planned to submit the below documentation as deliverables.
1. Non-disclosure agreements (NDAs) with various SD-WAN providers for technology review.

2. Master Service agreement (MSA) agreed with the SD-WAN partner.

3. Statement of works (SOW) agreed with the SD-WAN partner.

4. Detailed project plan.

5. Network architecture diagrams prepared, showing the SD-WAN in the production network.

6. Application integration documentation prepared.

7. An SD-WAN hardware installation guide produced.

8. Organizations network topology developed, including an SD-WAN network administration guide produced.

9. An SD-WAN Location support guide produced.

\section{iV. Revisions made based on Formative Evaluation Results}

The project team may need to perform some revision in their plan or test scenarios based on their observations or initial test results. Please refer below iterations as a reference.

Revision 1:

More test scenarios were included after initial testing of the SDWAN technology. 
The Project Team selected an SDWAN partner based on the features available in their product and various other factors like ease of installation. During the SDWAN Design phase, when the team started to test the application in the existing enterprise network, the group encountered a few challenges, as the application did not work as expected. The Network Team worked extensively with the SDWAN technical team to figure out what changes are required in the existing network configuration to accommodate new technology. The PM and the professional team decided to include more test scenarios based on the experience.It will also help to ensure they do not encounter any challenges in the rollout stage as that will cause an interruption to the operations, and it may take the whole project in jeopardy. This revision helped the project in a big way, and the team decided to do a few more design changes in the network architecture before going to the next phase.

Revision 2:

Perform the rollout in two weeks instead of three.

It is imperative to implement the new technology as soon as possible, especially before any big holiday season, as that is when most of the sales happen. The team had taken some extra time during the SDWAN design phase, and PM realized that with the current plan, they would not be able to complete the project as per the schedule. The PM met with the Leadership Team, and they collectively decided to request Onsite Tech partner to allocate extra resources to perform multiple installations at the same time at different locations. The project team has already worked extensively to develop the installation playbook and application test instructions that helped the installation crew to install with only a few issues. Due to the expedited schedule that the project members decided,the team was able to complete the project on time.

\section{Plan for Summative Evaluation}

According to NIU (n.d.), Summative assessment takes place after the project has been completed and provides information and feedback that sums up the teaching and learning process. Summative evaluations are more product-oriented and assess the final output, whereas formative assessment focuses on the process of completing the product.

With the help of inputs received from various stakeholders, including leadership, technical, and operations, the project manager performed Summative Evaluation at the end of the project. The PM evaluated the project from various aspects as per below.

- Compare proposed Vs. Actual Deliverables

- Budget Allocated Vs. Actual Spent

- Resources Allocated Vs. Actual

- Timelines (Planned Vs. Actual)
- Significant challenges encountered in various phases

- Impact on operations due to project activities

- Return on Investment (ROI)

- Associates feedback

The PM has planned to use this data to conduct a lessons learned session along with the Leadership Team, which will help the organization carry out future projects more efficiently.

\section{Vi. Project Reports and Evaluation Results}

The PM can plan to send reports and evaluation results to the below group of stakeholders.

First Stakeholder Group: Internal Technical Teams

This Stakeholder group is consists of two primary teams: IT Network and IT Operations

1. IT Network Engineering

2. Network architecture

3. Network administrators

Responsibility: IT network engineering

The organization's network engineering team should work closely with the SD-WAN technology partner to design the network; administrators will be responsible for the switch and appliance configurations. They will work as per the agreed implementation plan and scheduled tasks.

IT operations (server \& storage)

Server administrator

Storage and backup administrator

Responsibility: IT operations

The IT operations team will provide the necessary computer storage for hosting the application in the data center. The server administrator will integrate the SD-WAN platform with other enterprise applications such as Okta for single sign-on or monitoring tools like Solar winds for alert monitoring purposes. The storage and backup administrator will provide the capacity for the servers and will be responsible for adding any servers to the backup policy.

Reports \& Evaluation Results for this group:

The PM can plan to send below reports to this group using enterprise email.

- Daily Design reviews and architecture draft ( in SDWAN design phase)

- Network Architecture

- Application integration documentation

- Product information

- Product Performance Matrix

- Project Plan

- Weekly Project Updates

- Resource utilization

- Project Closure 
The PM will also schedule technical workshops with this group during the SDWAN design phase and weekly conference calls with all the stakeholders during the Initial implementation and Roll-out phase. The PMO (Project Management Office) will also create a common shared folder the enterprise google drive (Document sharing platform) where these reports will be stored, and any member can review these reports whenever they need to.

Second Stakeholder Group: Operations Support and Onsite Technicians

This Stakeholder group is consists of two primary teams: Operations Support and Onsite Technicians

Operations support

Technical support analyst

Support center leader

Responsibility: Operations support

The technical support analyst will work closely with the network team and the PM to install the SD-WAN hardware in all the locations. The technical support analyst will also assist the PM in coordinating the tasks and will collect feedback from the associates. The support center leader will be responsible for providing the necessary resources for the support staff and will conduct training on the new technology.

On-site technicians

Justification: on-site technicians

The on-site technical support team will be responsible for providing the necessary resources and tools for the installation of SD-WAN hardware at all the business and office locations. They will provide the necessary support, "on the ground," to the network administrator who will be making the required configuration changes remotely.

The PM can schedule daily installation workshops with this group during the SDWAN design phase to discuss the network topology and SDWAN installation playbook that can be used by the team members daily.

\section{Third Stakeholder Group: Project Leadership and PMO}

This Stakeholder group consists of Chief of Operations (COO), Vice President (VP) of IT and PMO, including dedicated PM for this project.

Chief of Operations (COO)

Responsibility: $\mathrm{COO}$

The COO will approve the budget allocated to the project and be responsible for providing any financial resources for the project's completion. The PM and the VP of Infrastructure will update the $\mathrm{COO}$ on the project's overall progress (Clarizen, 2017).In this project, the $\mathrm{COO}$ will be the main project sponsor, and PM will work with $\mathrm{COO}$ in case any changes are necessary in the allocated budget amount.

Vice President (VP) of IT
Responsibility: VP-IT

The VP- IT will work closely with all the technical teams and the PM to allocate the necessary organizational resources for project task completion. He will also approve changes in the network and application architecture, which may be required to complete the project.

Project management office

Project manager

Director - PMO

Responsibility: project management office

The PM will be responsible for the overall progress of the project. He will take care of preparing the project plan, scheduling tasks, and coordinating resources. He will also maintain the project budget and provide regular updates to the project stakeholders. He will also review the overall project portfolio for the organization along with the director of PMO (Project Management Office) to ensure that scheduled tasks do not clash with the major activities of other business areas.

The PM can plan to send below reports to this group using enterprise email.

- Initial Project Charter

- Cost-Benefit Analysis

- Project Plan

- Resource Allocation

- Risk Evaluation

- Product Evaluation reports

- Weekly Project Updates

- Resource utilization

- Business feedback

- Project Closure

The PM should invite all the stakeholders in the initial kick-off meeting of the project to discuss Project scope and his plan for budget and resource allocation. He should gather feedback from all the participants and make final adjustments before he shares the documents with the other groups involved in the project.

Fourth Stakeholder: Associates

Justification: Associates

An associate can be selected from each location to provide feedback on the overall hardware installation service during implementation and on network performance improvement following installation. The associate will also grant any exclusive access or permissions required for installinga new internet circuit or hardware device.

The PM will schedule a meeting with the selected associates to brief them on the project and what all is needed from them to make this project successful. The PM will also share the process of sharing feedback on product performance.

Fifth Stakeholder: SD-WAN technology Partner 
Justification: SD-WAN technology partner

The SD-WAN partner will work closely with the network architect during the initial network design. The partner will also provide support to the PM and network administrator in preparing training materials or making decisions on configuration changes.

The PM can plan to send below reports to this group using enterprise email.

- Daily Design reviews and architecture draft (in SDWAN design phase)

- Network Architecture

- Application integration documentation

- Product Performance Matrix

- Project Plan

- Weekly Project Updates

- Project Closure

The PM will involve technical team members from the SDWAN group in the technology workshops with the Network and IT Operations team so that both parties have clear information about their environment. The PM will also schedule product review discussions with the group as and when needed.

\section{Vil. Post-Implementation Description}

\section{a) Resource Requirement}

The project team will share the operations support plan in its handover documentation to the operations team and will request for below resources for post-implementation support.

\section{Onsite Support Team}

The onsite support team will be responsible for managing the day-to-day operational tasks related to network changes and monitoring all the alerts. They will be responsible for performing Level1 troubleshooting on all the incidents. This team will escalate the issue to the next level that is either Network or IT operations depending upon the type of alert.

\section{Network Administrator}

The Network Operations team will have multiple Network Administrators who will work as a point of escalation for the onsite support team. Few team members from this group can be involved in the initial network design, and they will have in-depth knowledge about the technology and its usage. They will be responsible for coordinating regular software code upgrades. They can engage in SDWAN technical support whenever they need an expert opinion on any support issues, or they need any explanation on how to use new features.

\section{IT Operations}

The IT operations will work as another escalation point for the support team to resolve any issues like communication failures with other enterprise applications. This team will be responsible for any new application integration that may come in the future as they have sufficient knowledge of the integration framework. This team can help Onsite Support to setup new performance alerts or add new sites to monitoring tools as and when needed.

\section{b) Maintenance Plan}

To maintain and administer the new technology, the project team can plan to share the documents with the IT Network operations and support team.

Short-term maintenance activities:

SDWAN Troubleshooting Guide

SDWAN -New site setup guide

Long-term maintenance activities:

SDWAN Hardware Maintenance Process

SDWAN -New site setup guide

SDWAN software upgrade process

These guides should contain detailed documentation with screenshots on how to maintain the product. A preview of the guide on how to measure the various performance parameters is shown below for reference: 
Please login to SDWAN application GUI (Graphic User Interface) using ----- link.

Click on Network Analytics to review bandwidth utilization.

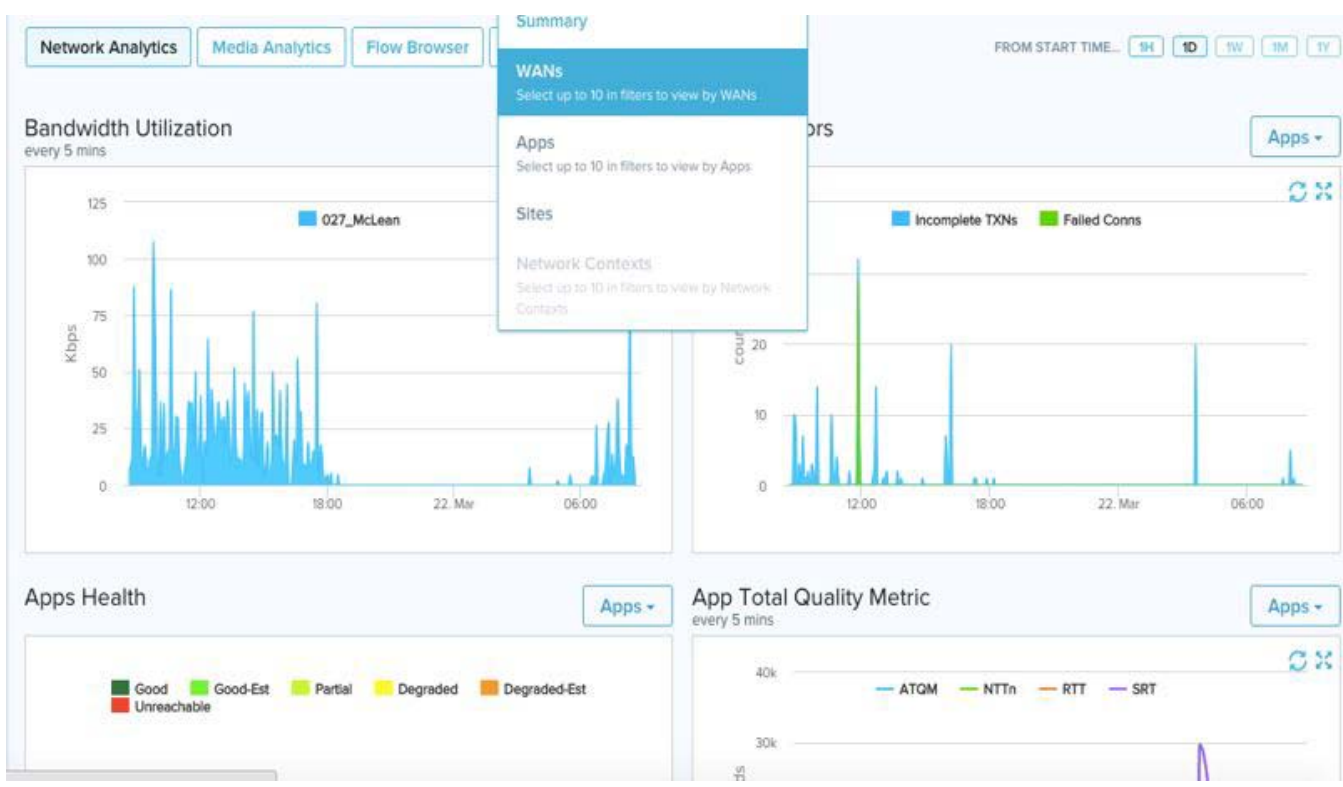

To view the application performance view Application Metric.

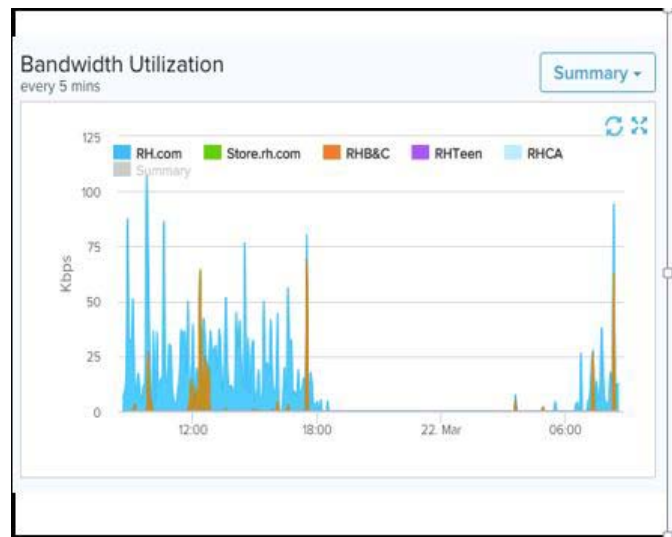

App Total Quality Metric every 5 mins

Apps -

2:

- ATOM $-\mathrm{NTT} \quad-\mathrm{RTT}-\mathrm{SRT}$

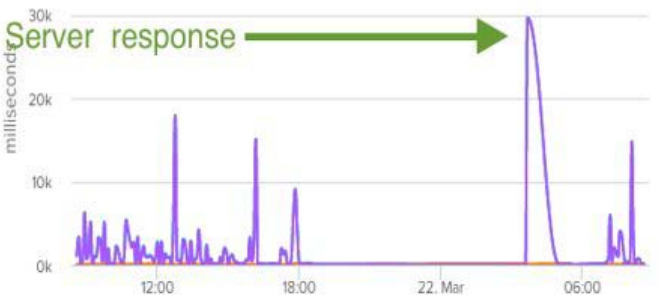

To check for the alerts, click on Faults (Alarms); below screenshot shows MPLS (Multiprotocol layer switching) path is not available.
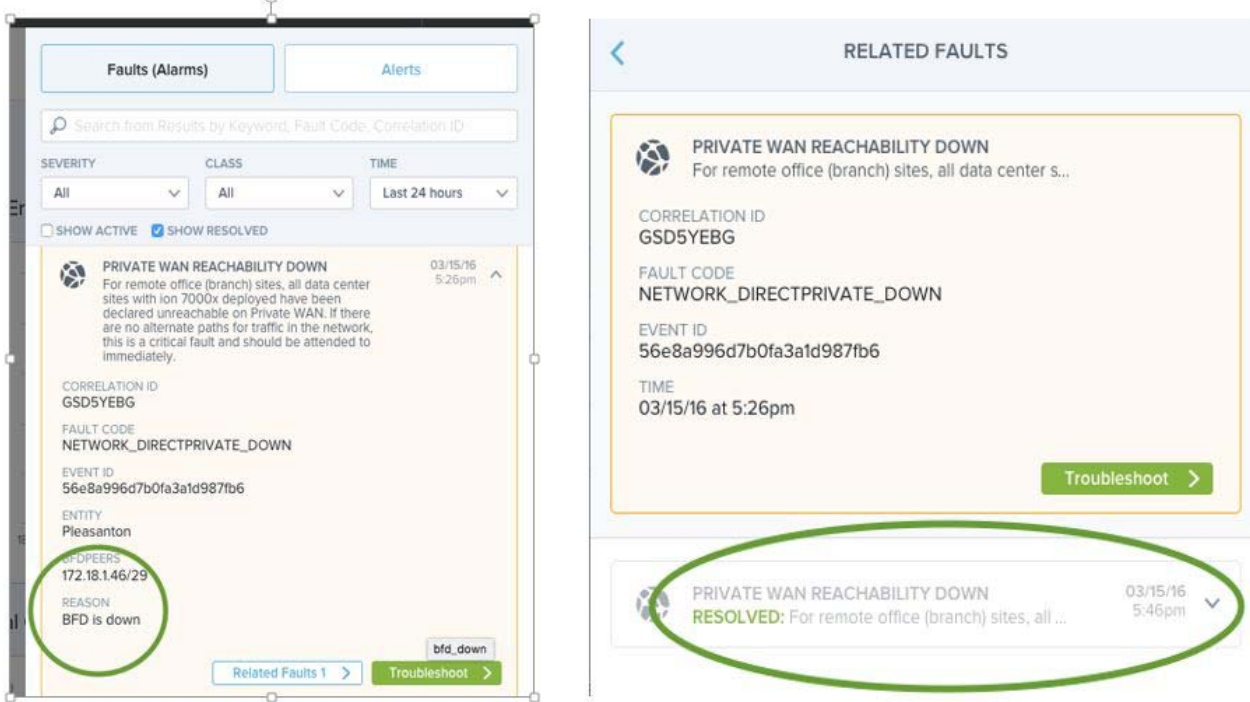
The project team will share a detailed document on how to manage the application upgrade process and how to contact the SDWAN support team, their working hours, and support contract details.

\section{Vili. Post-Implementation Project SUMMARY}

a) Deliverables to document the Plan and Process

The Project Team can plan to send below reports/data to all the stakeholders involved to share the success story of the project:

- Locations-Network Performance Report

- Network Incident report
- Sample Pictures that were taken at different locations after successful install

\section{- Associate feedback}

Please refer the below sample of a Network performance report of a location that was complaining about the network performance when they were using an older technology.

We have observed that after Circuit upgrade and SDWAN implementation, it has reduced the response time for our organization's website by almost fifty percent. Please refer below screenshot for a location taken from the OOKLA tool that is worldrenowned for network performance measurement.

Before Installation: Page Load was taking 7.94 seconds for $90 \%$ of the users.

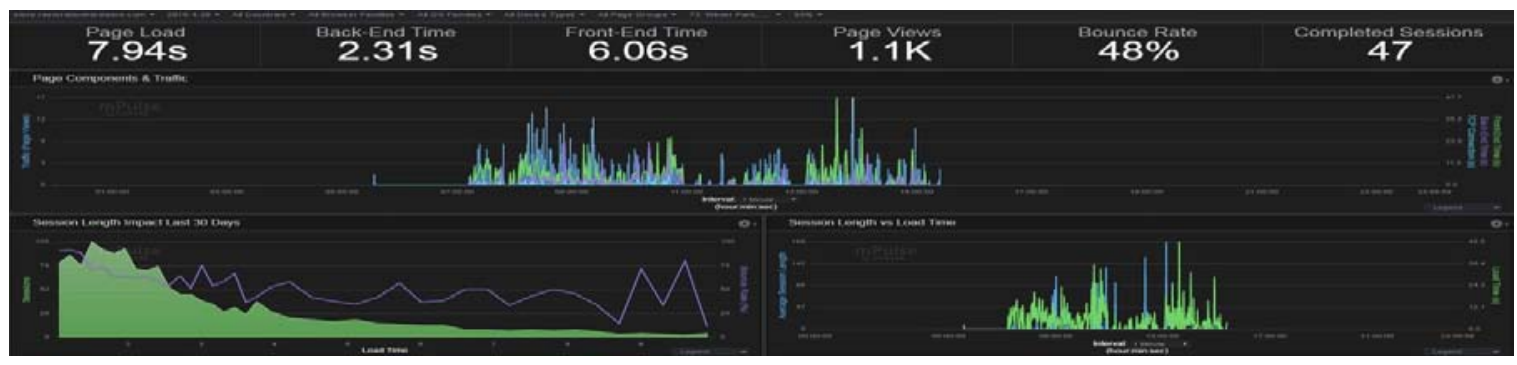

After Installation: Page Load time was reduced to 2.67 seconds for $90 \%$ of the users.

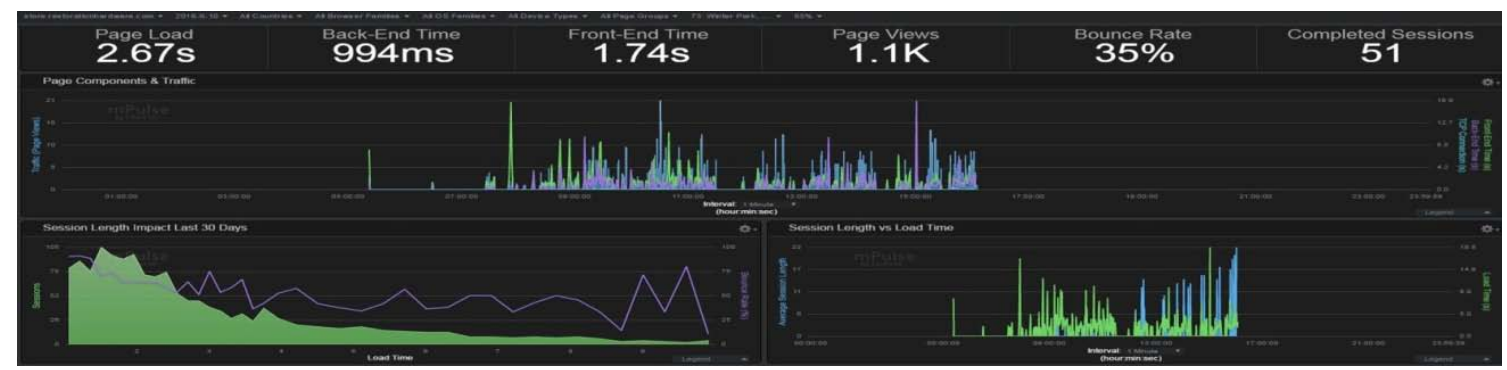

b) Criteria and Evaluation Framework

We can evaluate the overall success of the project based on the criteria shown below:

- Improvement in the network performance after completion.

- Ease of implementation of the new technology at the new sites.

- Ease of network administration
- Reduction in network incidents after the final rollout

- Overall operational and process improvements

- The vulnerability reports on the hardware and software.

Please refer below metrics as a reference to measure the proposed and actual outcomes of the project.

\begin{tabular}{|c|c|c|c|}
\hline Evaluation criterion & Proposed \% & Actual \% & Business Feedback \\
\hline Internet bandwidth upgrade & $35 \mathrm{M}$ & $40 \mathrm{M}$ & Positive \\
\hline Network reliability & $100 \%$ & $100 \%$ & No Issues \\
\hline Hardware reliability & $100 \%$ & $100 \%$ & No Issues \\
\hline Ease of installation & $40 \%$ & $30 \%$ & No Issues \\
\hline Ease of access & $50 \%$ & $60 \%$ & NA \\
\hline Network management & $50 \%$ & $70 \%$ & NA \\
\hline Security policies management & $60 \%$ & $80 \%$ & NA \\
\hline Vendor support & $50 \%$ & $40 \%$ & NA \\
\hline
\end{tabular}




\section{LEARNINGS}

According to Sabyasachi (n.d.) by collecting and publishing lessons the team learned while completing the previous project, your organization as a whole can benefit. You can help reduce the odds of other groups by making sure they do not repeat the same mistakes and provide insights into how various processes and procedures can be improved overtime. According to Rowe, S. F. \& Sikes, S. (2006), most project managers know the importance of capturing lessons learned; it is suitable for the team, organization, existing, and future projects. Lessons learned are the documented information that reflects both the positive and negative experiences of a project. They represent the organization's commitment to project management excellence and the project manager's opportunity to learn from the actual experiences of others I want to mention the below points that I learned from the process of completing this project.

- The more time we spend on initial design and testing, the more we increase the chances of success in completing the project on schedule and achieving our targets.

- We need to involve all the stakeholders from the beginning of the project.

- The PM should inform stakeholders about any changes in the budget, resource allocation, or times lines as soon as possible.

- It is essential to decide on the Project Scope, success criteria, and tools used at the beginning of the project.

- The process of lessons learned should be adapted from the initial implementation stage (not at the end of the project) so that the team can review "What went wrong" and "What needs to be improved." This project manager should use the same forum to discuss "What went right."

- It is better to keep some buffer in terms of resources or timelines in each phase and some cushion in the overall project timelines.

\section{References Références Referencias}

1. Clarizen (2017) Blog - Who are Project Management Stakeholders. Retrieved from - https:// www.clarizen.com/project-management-stake holders/

2. MOP (n.d.) Blog: Project Closure Phase. Retrieved from https://blog.masterofproject.com/projectclosure-phase/

3. NIU (n.d.) Report-Formative and Summative Assessment. Retrieved from https://www.niu.edu/ facdev/_pdf/guide/assessment/formative\%20and_s ummative assessment.pdf.

4. Rowe, S. F. \& Sikes, S. (2006). Lessons learned: taking it to the next level. Paper presented at PMI $®$
Global Congress 2006- North America, Seattle, WA. Newtown Square, PA: Project Management Institute. Retrieved from https://www.pmi.org/learning/ library/ lessons-learned-next-level-communicating-7991.

5. Sabyasachi (n.d.) Blog- Best Practices for Preparing a Lessons Learned Document. Retrieved from https://www.simplilearn.com/practices-for-preparing - a-lessons-learned-document-article.

6. Wikipedia (n.d.) Database- SD-WAN. Retrieved from: https://en.wikipedia.org/wiki/SD-WAN. 